\title{
Superiority of Prothrombin Complex Concentrate versus Frozen Fresh Plasma in Cardiology Patients with Warfarin Intoxication-Observational Study
}

\author{
Alexandre de Matos Soeiro*, Maria Cristina César, Bruno Biselli, Aline Siqueira Bossa, \\ Tatiana de Carvalho Andreucci Torres Leal, Maria Carolina Feres de Almeida Soeiro, \\ Carlos V. Serrano Jr., Ludhmila Abraão Hajjar, Múcio Tavares Oliveira Jr.
}

Emergency Unit-Heart Institute-University of São Paulo Medical School, São Paulo, Brazil

Email: *alexandre.soeiro@bol.com.br

How to cite this paper: de M. Soeiro, A., César, M.C., Biselli, B., Bossa, A.S., de C.A.T. Leal, T., de A. Soeiro, M.C.F., Serrano Jr., C.V., Hajjar, L.A. and Oliveira Jr., M.T. (2017) Superiority of Prothrombin Complex Concentrate versus Frozen Fresh Plasma in Cardiology Patients with Warfarin Intoxication-Observational Study. Open Journal of Emergency Medicine, 5, 75-84. https://doi.org/10.4236/ojem.2017.52007

Received: May 17, 2017

Accepted: June 23, 2017

Published: June 26, 2017

Copyright $\odot 2017$ by authors and Scientific Research Publishing Inc. This work is licensed under the Creative Commons Attribution International License (CC BY 4.0).

http://creativecommons.org/licenses/by/4.0/

\section{(c) (i) Open Access}

\begin{abstract}
Objective: The objective of this study was to analyse the reversibility of the anticoagulant effect of warfarin by comparing prothrombin complex concentrate (PCC) versus frozen fresh plasma (FFP) in cardiology patients with serious warfarin intoxication. Methods: This was an observational and retrospective study comprising 67 patients (18 in group I [PCC] and 49 in group II [FFP]). The primary endpoint was the reversal of anticoagulant effect of warfarin after 2 and 24 hours of PCC or FFP administration. Comparisons between the groups were made using T-test and Q-square. Multivariate analyses were conducted using logistic regression, and the results were considered significant when $p<0.05$. Complementary analysis was performed using the ROC curve, calculating the area under the curve (AUC), and calculating the cut-off score for the relation between PCC (UI/kg) or FFP $(\mathrm{ml} / \mathrm{kg})$ and INR reversibility. Results: The medium dose used was $27.6 \mathrm{UI} / \mathrm{kg}$ of PCC and 14.5 $\mathrm{ml} / \mathrm{kg}$ of FFP. Significant differences were observed between groups I and II in the INR reversibility measurements after 2 hours $(33.3 \%$ vs. $6.1 \%, p=0.001)$ and 24 hours (38.9\% vs. $12.2 \%, p=0.009)$ as well as in the occurrence of pulmonary edema ( $5.6 \%$ vs. $42.9 \%$, OR $=11.10, p=0.04$ ). The AUC for PCC was 0.891 (CI 95\% [0.72 - 1.0]), and for FFP, it was 0.291 (CI 95\% [0.09- 0.49]). Conclusions: PCC is better than FFP treatment in reversing the warfarin intoxication after 2 and 24 hours of administration. Furthermore, PCC showed lower pulmonary edema in cardiology patients.
\end{abstract}

\section{Keywords}

Intoxication, Warfarin, Fresh Frozen Plasma,

Prothrombin Complex Concentrate 


\section{Introduction}

Bleeding in patients using warfarin is common and is often associated with the risk of death. The comparison between the in vivo use of prothrombin complex concentrate (PCC) and frozen fresh plasma (FFP) in cardiology patients remains uncertain. Recent studies have shown superiority of prothrombin complex concentrate (PCC) over frozen fresh plasma (FFP) administration in situations, such as in surgical patients or patients with intracranial bleeding, reducing transfusion requirements and even mortality [1]-[9]. Furthermore, PCC reduces the risk of transmission of infective agents. However, PCC can be associated with a higher incidence of thrombogenic events, which is a concern for cardiology patients with atrial fibrillation or prosthetic valves.

The objective of this study was to analyse the reversibility of the anticoagulant effect of warfarin by comparing PCC versus FFP in cardiology patients with serious warfarin intoxication.

\section{Methods}

\subsection{Study Population}

This study was an observational, unicentric and retrospective data bank analysis study performed in a tertiary health centre involving 67 patients, conducted between January 2015 and January 2016. The study included all patients with serious bleeding related to warfarin use when the prothrombin time/INR values were more than 20 or upon occurrence of haemorrhagic stroke, haemorrhagic shock, retroperitoneal bleeding, a decrease of $2 \mathrm{mg} / \mathrm{dL}$ in the haemoglobin levels, or a transfusion of 2 or more red blood cell concentrates. There were no exclusion criteria.

Patients were divided into two groups, the patients who received PCC (group I, $n=18$ ) and the patients who received FFP (group II, $n=49$ ). In addition to PCC or FFP, all patients received vitamin $\mathrm{k}(10 \mathrm{mg} \mathrm{EV})$ within the first hour. Reversibility was achieved when INR $<1.5$.

The study was approved by the ethics and research committee, and informed consent was obtained from the patient or a family member in all cases. This study was registered in clinicaltrial.govas ROAD-BRAZIL Registry-NCT02753023.

\subsection{Analytical Methods}

The following patient data were obtained: age; sex; weight; heart rate; systolic arterial pressure; medications used; platelet count; and the creatinine, C-reactive protein, and haemoglobin levels. The patient's histories of smoking, alcoholism, diabetes, systemic arterial hypertension, dyslipidemia, atrial fibrillation, heart failure, stroke, recent surgery, and implantation of prosthetic mechanical valve were also considered. The INR at admission, left ventricle ejection fraction, red blood cell transfusions, administration of endovenous fluids and the use of vasoactive drugs were also noted (Table 1). As INR is a standardized value calculated as follow: INR $=\left(\text { prothrombin }_{\text {test }} / \text { prothrombin }_{\text {control }}\right)^{\text {ISI }}$. 
Table 1. Baseline characteristics of patients according with use of PCC or FFP.

\begin{tabular}{|c|c|c|c|}
\hline & PCC & FFP & $p$ \\
\hline Male (\%) & 33.3 & 38.8 & 0.683 \\
\hline Age (median) & $65.6 \pm 11.68$ & $67.8 \pm 14.54$ & 0.539 \\
\hline BMI $\left(\mathrm{kg} / \mathrm{m}^{2}\right)$ (median) & $26.2+7.56$ & $27.2 \pm 8.27$ & 0.222 \\
\hline CHADSVASC2 (median) & $3.28 \pm 1.74$ & $3.24 \pm 2.05$ & 0.946 \\
\hline HASBLED (median) & $1.33 \pm 1.16$ & $1.13 \pm 0.95$ & 0.822 \\
\hline Mechanical valves (\%) & 5.9 & 4.1 & 0.796 \\
\hline Previous thromboembolic event (\%) & 27.8 & 16.3 & 0.293 \\
\hline Thrombus of LV (\%) & 11.1 & 2 & 0.112 \\
\hline Deep vein thrombosis (\%) & 11.1 & 2 & 0.112 \\
\hline Valvular disease (\%) & 22.2 & 24.5 & 0.847 \\
\hline Atrial fibrilation (\%) & 66.7 & 91.8 & 0.01 \\
\hline Diabetes mellitus (\%) & 22.2 & 32.7 & 0.408 \\
\hline Hypertension (\%) & 55.5 & 75.5 & 0.114 \\
\hline Heart failure (\%) & 44.4 & 28.6 & 0.22 \\
\hline Dyslipidemia (\%) & 27.8 & 16.3 & 0.293 \\
\hline Etilism (\%) & 0 & 2 & 0.541 \\
\hline Tabagism (\%) & 5.6 & 16.3 & 0.252 \\
\hline Previous stroke (\%) & 22.2 & 20.4 & 0.871 \\
\hline Recent surgery (\%) & 5.6 & 2 & 0.454 \\
\hline Previous acute myocardial infarction (\%) & 22.2 & 30.6 & 0.499 \\
\hline Previous gastrointestinal bleeding (\%) & 0 & 6.1 & 0.283 \\
\hline Heart rate (median) & $85.2 \pm 18.92$ & $83.9 \pm 16.45$ & 0.803 \\
\hline Systolic arterial pressure (mmHg) (median) & $114.3 \pm 23.03$ & $111.6 \pm 25.28$ & 0.679 \\
\hline Hemoglobin (mg/dL) (median) & $8.78 \pm 2.88$ & $10.53 \pm 3.23$ & 0.029 \\
\hline Platelets $\left(\times 10^{3} / \mathrm{mm}^{3}\right)$ (median) & $241 \pm 122.34$ & $252 \pm 145.67$ & 0.671 \\
\hline INR (median) & $12.48 \pm 6.88$ & $12.19 \pm 7.23$ & 0.007 \\
\hline Creatinin (mg/dL) (median) & $1.91 \pm 1.05$ & $1.6 \pm 1.24$ & 0.932 \\
\hline C-reactive protein $(\mathrm{mg} / \mathrm{dL})$ (median) & $49.1 \pm 67.96$ & $59.7 \pm 72.35$ & 0.605 \\
\hline LVEF (\%) (median) & $47.3 \pm 15.29$ & $52.6 \pm 13.54$ & 0.228 \\
\hline $\mathrm{ml} / \mathrm{kg}$ of cristaloids (median) & $15.4 \pm 8.73$ & $23.1 \pm 13.27$ & 0.056 \\
\hline Use of dobutamine (\%) & 16.7 & 11.9 & 0.808 \\
\hline Use of norepinephrine (\%) & 38.9 & 8.2 & 0.003 \\
\hline Aspirin (\%) & 11.1 & 24.5 & 0.233 \\
\hline B-blocker (\%) & 83.3 & 69.4 & 0.254 \\
\hline Proton pump inhibitor (\%) & 55.6 & 51 & 0.742 \\
\hline
\end{tabular}

Legend: $\mathrm{PCC}=$ prothrombin complex concentrate; FFP = frozen fresh plasma; $\mathrm{BMI}=$ body mass index; LV $=$ left ventricle; $\mathrm{INR}=$ prothrombin time; $\mathrm{EF}=$ ejection fraction. 
The primary endpoint was the reversibility of the anticoagulant effect of warfarin after 2 and 24 hours of PCC or FFP treatment. The secondary end points included the occurrence of an allergic reaction, thromboembolic events, acute renal failure, stroke, nosocomial infections, transfusion-related acute lung injury [TRALI], pulmonary edema, or death. Acute renal failure was defined as an abrupt (within 48 hours) reduction in kidney function, which is currently defined as an absolute increase in serum creatinine levels of more than or equal to $0.3 \mathrm{mg} / \mathrm{dl}$, a percentage increase in serum creatinine of more than or equal to $50 \%$, or a reduction in urine output (documented oliguria of less than $0.5 \mathrm{ml} / \mathrm{kg}$ per hour for more than six hours). Stroke was considered in cases of new focal neurological deficits in the participants, confirmed by cranial computerized tomography. TRALI was defined as the acute onset of non-cardiogenic pulmonary edema within 6 hours of transfusion of blood products. Pulmonary edema was considered cardiogenic only when there was the characteristic low oxygen saturation, and the chest X-rays exhibited fluid in the alveolar walls, Kerley B lines, increased vascular shadowing in a classical batwing perihilar pattern, upper lobe diversion and pleural effusions. Allergy was defined as experiencing difficulty in breathing, skin rashes or shock after administration of the drug. Nosocomial infections were defined as any type of infection acquired after 48 hours of hospital admission.

Blood was sampled immediately after admission before administration of medications (baseline) and after 2 and 24 hours of drug administration, according to the institutional protocols. The PCC used was an octaplex (Octapharma Inc., Switzerland).

\subsection{Statistical Analysis}

Descriptive analysis of the data collected includes the median and the minimum and maximum values. Comparison between the groups was made using T-test and Q-square. If the Kolmogorov-Smirnov tests confirmed normal distribution, continuous variables were summarized using the mean \pm standard deviation and were compared using Student's t-test for independent samples. The MannWhitney $\mathrm{U}$ test was used to compare continuous variables if they were not normally distributed.

The multivariate analyses were performed on the clinical outcomes by logistic regression only if significant univariate analyses were observed. The results were considered significant when $p<0.05$. As shown in Table 1 , the variables include all baseline characteristics with significant differences between the groups.

Complementary analysis was conducted using the Receiver Operating Characteristic (ROC) curve, calculating the area under the curve (AUC) and calculating the cut-off score for the relation between PCC (UI/ $\mathrm{kg})$ or FFP $(\mathrm{ml} / \mathrm{kg})$ administration and INR measurements after 2 and 24 hours. The confidence interval used was $95 \%$.

All statistical analyses were performed using statistical software program SPSS v10.0. 


\section{Results}

The median age of the participants was 68 years, and approximately $37 \%$ were male patients with a median left ventricle ejection fraction of $52 \%$. The most common case of bleeding was upper gastrointestinal bleeding (31.7\%), followed by muscular $(24.4 \%)$, urinary $(18.1 \%)$ and intracranial $(13.2 \%)$ bleeding. The medium dose used was 27.6 UI/kg for PCC and $14.5 \mathrm{ml} / \mathrm{kg}$ for FFP. The median CHADSVASC score was 3.2, and the HASBLED score was 1.2.

We observed significant differences between groups I and II in the prevalence of atrial fibrillation $(66.7 \%$ vs. $91.8 \%, p=0.01)$, haemoglobin levels $(8.78 \mathrm{mg} / \mathrm{dL}$ vs. $10.53 \mathrm{mg} / \mathrm{dL}, p=0.029)$, INR values at admission (12.48 vs. $12.19, p=0.007)$ and use of norepinephrine (38.9\% vs. $8.2 \%, p=0.003$ ) (Table 1$)$.

Significant differences were observed between groups I and II in INR reversibility after $2(33.3 \%$ vs. $6.1 \%, p=0.001)$ and 24 hours $(38.9 \%$ vs. $12.2 \%, p=$ $0.009)$. The incidence of pulmonary edema between groups I and II was different as well $(5.6 \%$ vs. $42.9 \%, \mathrm{OR}=11.10, p=0.04)$. The univariate and multivariate analyses are shown in Table 2.

After 2 hours, the AUCs calculated from the ROC curve were 0.891 (CI 95\% [0.72 - 1.0]) and 0.291 (CI 95\% [0.09 - 0.49]) for PCC and FFP, respectively. The cut-off scores were $30.8 \mathrm{UI} / \mathrm{kg}$ for PCC (sensitivity $=83.3 \%$ and specificity $=$ $92 \%$ ) and $11.76 \mathrm{ml} / \mathrm{kg}$ (sensitivity $=66.7 \%$ and specificity $=36 \%$ ) for FFP. After 24 hours, the AUC for PCC was 0.744 (CI 95\% [0.52 - 0.97]) and for FFP was 0.503 (CI 95\% [0.30 - 0.51]). The cut-off scores were $24.03 \mathrm{UI} / \mathrm{kg}$ for PCC (sensitivity $=87.5 \%$ and specificity $=64 \%$ ) and $15.76 \mathrm{ml} / \mathrm{kg}$ for FFP (sensitivity = $57.1 \%$ and specificity $=61 \%)($ Figure 1$)$.

Table 2. (a) Univariate analysis with secondary events comparing PCC versus FFP; (b) Multivariate analysis of pulmonar edema comparing PCC versus FFP.

(b)

\begin{tabular}{cccc}
\hline & PCC & FFP & $p$ \\
\hline Mortality (\%) & 16.7 & 12.2 & 0.638 \\
Allergy (\%) & 5.8 & 2.1 & 0.454 \\
Thromboembolic events (\%) & 0 & 2.1 & 0.541 \\
Acute renal failure (\%) & 66.7 & 59.2 & 0.577 \\
Stroke (\%) & 0 & 2.1 & 0.541 \\
Nosocomial infection (\%) & 77.8 & 69.4 & 0.499 \\
TRALI (\%) & 0 & 2.1 & 0.541 \\
Pulmonary edema (\%) & 5.6 & 42.9 & 0.04 \\
Combined events (\%) & 83.3 & 83.7 & 0.973 \\
\hline
\end{tabular}

(b)

\begin{tabular}{cccccc}
\hline & PCC & FFP & OR & CI 95\% & $p$ \\
\hline Pulmonary edema (\%) & 5.6 & 42.9 & 11.1 & $1.04-11.9$ & 0.04 \\
\hline
\end{tabular}

Legend: $\mathrm{PCC}=$ prothrombin complex concentrate; FFP = frozen fresh plasma; $\mathrm{CI}=$ confidence interval; $\mathrm{OR}$ $=$ odds ratio. 


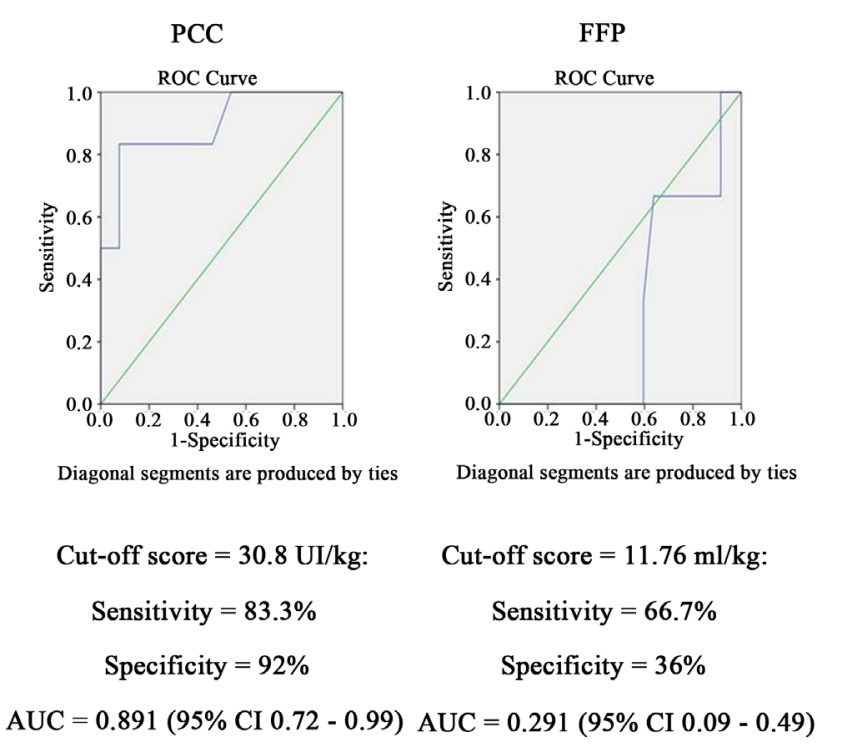

(a)

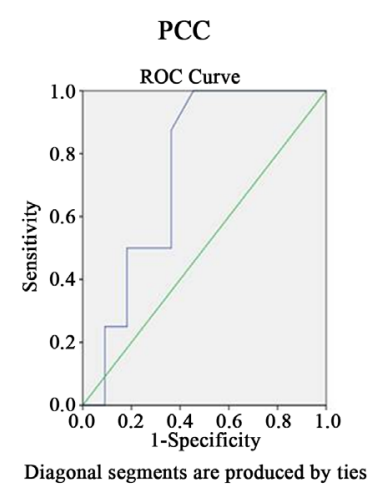

Cut-off score $=24.03 \mathrm{UI} / \mathrm{kg}$ :

Sensitivity $=87.5 \%$

Especificity $=64 \%$

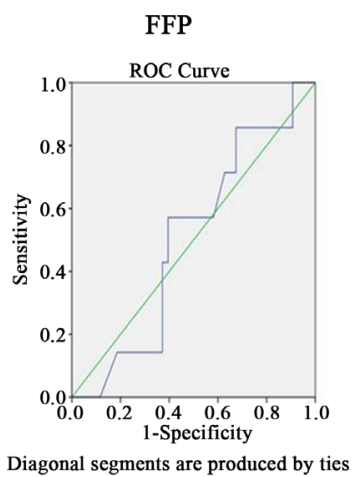

Cut-off score $=15.76 \mathrm{ml} / \mathrm{kg}$ :

Sensitivity $=57.1 \%$

Especificity $=61 \%$

$\mathrm{AUC}=0.744(95 \%$ CI $0.52-0.97) \mathrm{AUC}=0.503(95 \%$ CI $0.30-0.51)$

(b)

Figure 1. ROC curve of reversibility of INR after 2 and 24 hours comparing PCC versus FFP. (a) Reversibility after 2 hours; (b) Reversibility after 24 hours. Legend: PCC = prothrombin complex concentrate; FFP = frozen fresh plasma; AUC=area under curve.

\section{Discussion}

In this study, we present results that are different from those suggested by the recent data. According to our results, the use of PCC lowered the INR measurements more than those of FFP after 2 and 24 hours of administration and with more regularity and predictability. The number of thromboembolic events did not increase with PCC administration, and a reduction in pulmonary edema was observed.

Karaca et al. [2] in 2014 published a prospective study, which included 40 patients with gastrointestinal haemorrhage related to warfarin use. Patients were divided into groups based on the use of either PCC (25 - 50 UI/kg) or FFP (10 $15 \mathrm{ml} / \mathrm{kg}$ ). After 2 and 6 hours of administration, PCC treatment showed better results than FFP (INR values for PCC and FFP after 2 hours $=1.53$ vs. $4.5, p<$ 0.01 ; INR values after 6 hours $=1.52$ vs. $2.41, p<0.01$, respectively). Endoscopic analysis showed that the number of patients with active bleeding was zero in case of PCC administration compared to 7 with FFP administration [2]. These findings are similar to ours, showing the superiority of PCC treatment in lowering the INR values after administration.

In neurologic patients, the use of PCC has demonstrated more benefits than the use of FFP [4] [8] [10] [11]. In 2014, a prospective and observational study involving 64 patients with intracranial haemorrhage related to warfarin use, compared the reversal (INR $<1.4$ ) and clinical outcomes of PCC (median of 48 $\mathrm{UI} / \mathrm{kg}$ ) and FFP (median of $12.5 \mathrm{ml} / \mathrm{kg}$ ) treatments. The reversal effect was similar, with $88 \%$ and $84 \%$ patients showing INR values less than 1.4 after PCC and FFP administrations, respectively. However, the use of FFP was related to a higher number of cases of bleeding $(52 \%, \mathrm{OR}=5.0, p=0.006)$ than the use of 
PCC $(6 \%, \mathrm{OR}=0.1, p=0,033)$. After 3 months, the use of PCC was associated with a lower risk of death or severe disability [4]. Different from our observations and the majority of studies, the use of FFP demonstrated a good rate of correction in the coagulogram. The administration of PCC was more effective in reduce bleeding and increasing clinical outcomes.

In another retrospective study published in Germany, 50 patients requiring urgent oral anticoagulation reversal or management of perioperative coagulopathic bleeding received PCC treatment (median dose of $1500 \mathrm{UI}$ ). The median PT value decreased from 2.8 to $1.5(p<0.001)$ after PCC administration. There were no major bleeding and thrombotic events related to the surgeries. Furthermore, a correlation was observed between the use of PCC and stabilization of the median arterial pressure [7]. This study demonstrated the safe use of PCC in surgical patients using warfarin. Under some circumstances, the use of PCC showed complete reversal of the anticoagulant effect of warfarin, demonstrating that PCC is an ideal choice for managing the effects of warfarin.

Similarly, in 2016, Cappabianca et al. [12], compared the use of PCC (median dose $1500 \mathrm{UI}$ ) and FFP (median dose $2 \mathrm{U}$ ) to manage bleeding after cardiac surgery in an observational study with 225 patients. They observed less blood loss with the use of PCC $(836 \mathrm{ml})$ than with FFP $(935 \mathrm{ml})(p<0.0001)$. The use of PCC was related to less red blood transfusion ( $O R=0.5 ; 95 \%$ CI $0.31-0.80)$ but higher acute renal failure $(\mathrm{OR}=1.44 ; 95 \% \mathrm{CI} 1.02-2.05)$. Mortality was the same for both PCC and FFP [12].

Although PCC has been associated with better reversal of coagulopathy induced by warfarin, the impact of PCC on real clinical outcomes is not clearly demonstrated [8] [9] [13]. In 2014, Fong et al. [9] in a historical cohort study compared patients with intracranial haemorrhage related to warfarin who received either PCC or FFP. After 24 hours, the median INR value changed from 2.8 to 1.2 upon PCC administration. The rate of neurological deterioration was $17.4 \%$ with PCC compared to $45.5 \%$ with FFP $(p=0.027)$. The mortality rate was also lower with PCC administration, but the difference was not significant. There were no thrombotic problems [9]. How FFP is not a pure composite, maybe other substances could disturb coagulation properties, becoming it less effective.

To compare the clinical outcomes of PCC and FFP treatments, a group in New Zealand used an improved reversal protocol in patients with intracranial haemorrhage. The data from 88 patients with median INR value 2.9 were analysed, and a higher reduction in mortality rate was observed with PCC than with FFP administration $(\mathrm{HR}=0.25, p=0.01)$. When PCC was administered sooner, the benefits trended to be higher [8].

Our work did not show a reduction in mortality rate, possibly due to the small number of patients participating in the study. Nevertheless, the incidence of pulmonary edema was higher with FFP than with PCC in the cardiology patients at the tertiary complex centre where the study was conducted.

Although the dose of PCC $(27.6 \mathrm{UI} / \mathrm{kg})$ used in this study was lower than the 
dose (35 - $50 \mathrm{UI} / \mathrm{kg})$ established for the full effect, its influence on anticoagulation reversal was better than the effect of the full dose of FFP $(14.5 \mathrm{ml} / \mathrm{kg})$. Similar results were reported by a retrospective study involving 103 patients with warfarin intoxication who received only 1,000 UI of PCC, which was considered a sub-optimal dose. The INR values were reduced to less than 1.5 and between 1.6 and 2.0 for $48.1 \%$ and $43.7 \%$ of the participants, respectively. Bleeding stopped in $83.5 \%$ of patients [14]. In our study, patients that used PCC had lower haemoglobin levels and more previous thromboembolic events, showing higher complexity and morbidity than FFP group. Even so, mortality rates were the same between groups.

A limiting factor in the widespread use of PCC has been its high cost. A cost-effectiveness analysis of UK National Health Service showed that in patients with warfarin-related bleeding (intracranial, retroperitoneal or gastrointestinal), the use of PCC comprises only $15 \%$ of the total cost of treatment. The cost per life-year gained was estimated to be $£ 1000$ to $£ 2000$ [15]. Therefore, despite the higher initial cost of PCC, its use could be encouraged because of the increased overall cost-effectiveness, safety, better reversal effect and favourable prognosis.

\section{Limitations}

This study has some limitations, such as the design was observational and had a small number of patients. The groups were different in some baseline characteristics. Additionally, we did not control the doses of PCC or FFP that the patients received. All medications used in the patients were administered according to the preference of the physician. The rationale behind which medications were administered was not described. Furthermore, this study was not designed to describe clinical outcomes.

\section{Conclusion}

In summary, PCC is better than FFP in reversing warfarin intoxication after 2 and 24 hours of administration. Furthermore, PCC showed lower pulmonary edema in cardiology patients.

\section{Fund}

This research received no specific grant from any funding agency in the public, commercial, or not-for-profit sectors.

\section{References}

[1] Cabral, K.P., Fraser, G.L., Duprey, J., Gibbons, B.A., Hayes, T., Florman, J.E., et al. (2013) Prothrombin Complex Concentrates to Reverse Warfarin-Induced Coagulopathy in Patients with Intracranial Bleeding. Clinical Neurology and Neurosurgery, 115, 770-774. https://doi.org/10.1016/j.clineuro.2012.07.006

[2] Karaca, M.A., Erbil, B. and Ozmen, M.M. (2014) Use and Effectiveness of Prothrombin Complex Concentrates vs Fresh Frozen Plasma in Gastrointestinal Hemorrhage Due to Warfarin Usage in the ED. The American Journal of Emergency Medicine, 32, 660-664. https://doi.org/10.1016/j.ajem.2014.02.016 
[3] Parry-Jones, A.R., Di Napoli, M., Goldstein, J.N., Schreuder, F.H., Tetri, S., Tatlisumak, T., et al. (2015) Reversal Strategies for Vitamin K Antagonists in Acute Intracerebral Hemorrhage. Annals of Neurology, 78, 54-62.

https://doi.org/10.1002/ana.24416

[4] Frontera, J.A., Gordon, E., Zach, V., Jovine, M., Uchino, K., Hussain, M.S., et al. (2014) Reversal of Coagulopathy Using Prothrombin Complex Concentrates Is Associated with Improved Outcome Compared to Fresh Frozen Plasma in Warfarin-Associated Intracranial Hemorrhage. Neurocritical Care, 21, 397-406.

https://doi.org/10.1007/s12028-014-9972-0

[5] Frontera, J.A., Lewin, J.J., Rabinstein, A.A., Aisiku, I.P., Alexandrov, A.W., Cook, A.M., et al. (2016) Guideline for Reversal of Antithrombotics in Intracranial Hemorrhage: A Statement for Healthcare Professionals from the Neurocritical Care Society and Society of Critical Care Medicine. Neurocritical Care, 24, 6-46. https://doi.org/10.1007/s12028-015-0222-x

[6] Barillari, G., Pasca, S., Barillari, A. and De Angelis, V. (2012) Emergency Reversal of Anticoagulation: From Theory to Real Use of Prothrombin Complex Concentrates. A Retrospective Italian Experience. Blood Transfusion, 10, 87-94.

[7] Schick, K.S., Fertmann, J.M., Jauch, K.W. and Hoffmann, J.N. (2009) Prothrombin Complex Concentrate in Surgical Patients: Retrospective Evaluation of Vitamin K Antagonist Reversal and Treatment of Severe Bleeding. Critical Care, 13, R191. https://doi.org/10.1186/cc8186

[8] Hanger, H.C., Geddes, J.A., Wilkinson, T.J., Lee, M. and Baker, A.E. (2013) Warfarin-Related Intracerebral Haemorrhage: Better Outcomes When Reversal Includes Prothrombin Complex Concentrates. Internal Medicine Journal, 43, 308-316. https://doi.org/10.1111/imj.12034

[9] Fong, W.C., Lo, W.T., Ng, Y.W., Cheung, Y.F., Wong, G.C., Ho, H.F., et al. (2014) The Benefit of prothrombin complex Concentrate in Decreasing Neurological Deterioration in Patients with Warfarin-Associated Intracerebral Haemorrhage. Hong Kong Medical Journal, 20, 486-494.

[10] Joseph, B., Pandit, V., Khalil, M., Kulvatunyou, N., Aziz, H., Tang, A., et al. (2015) Use of Prothrombin Complex Concentrate as an Adjunct to Fresh Frozen Plasma Shortens Time to Craniotomy in Traumatic Brain Injury Patients. Neurosurgery, 76, 601-607. https://doi.org/10.1227/NEU.0000000000000685

[11] Steiner, T., Poli, S., Griebe, M., Hüsing, J., Hajda, J., Freiberger, A., et al. (2016) Fresh Frozen Plasma versus Prothrombin Complex Concentrate in Patients with Intracranial Haemorrhage Related to Vitamin K Antagonists (INCH): A Randomised Trial. The Lancet Neurology, 15, 566-573. https://doi.org/10.1016/S1474-4422(16)00110-1

[12] Cappabianca, G., Mariscalco, G., Biancari, F., Maselli, D., Papesso, F., Cottini, M., et al. (2016) Safety and Efficacy of Prothrombin Complex Concentrate as First-Line Treatment in Bleeding after Cardiac Surgery. Critical Care, 20, 5. https://doi.org/10.1186/s13054-015-1172-6

[13] Ogawa, S., Szlam, F., Ohnishi, T., Molinaro, R.J., Hosokawa, K., Tanaka. K.A. (2011) A Comparative Study of Prothrombin Complex Concentrates and Fresh-Frozen Plasma for Warfarin Reversal under Static and Flow Conditions. Thrombosis and Haemostasis, 106, 1215-1223. https://doi.org/10.1160/TH11-04-0240

[14] Varga, C., Al-Touri, S., Papadoukakis, S., Caplan, S., Kahn, S. and Blostein, M. (2013) The Effectiveness and Safety of Fixed Low-Dose Prothrombin Complex Concentrates in Patients Requiring Urgent Reversal of Warfarin. Transfusion, 53, 
1451-1458. https://doi.org/10.1111/j.1537-2995.2012.03924.x

[15] Guest, J.F., Watson, H.G. and Limaye, S. (2010) Modeling the Cost-Effectiveness of Prothrombin Complex Concentrate Compared with Fresh Frozen Plasma in Emergency Warfarin Reversal in the United Kingdom. Clinical Therapeutics, 32, 2478-2493. https://doi.org/10.1016/j.clinthera.2011.01.011

Submit or recommend next manuscript to SCIRP and we will provide best service for you:

Accepting pre-submission inquiries through Email, Facebook, LinkedIn, Twitter, etc. A wide selection of journals (inclusive of 9 subjects, more than 200 journals)

Providing 24-hour high-quality service

User-friendly online submission system

Fair and swift peer-review system

Efficient typesetting and proofreading procedure

Display of the result of downloads and visits, as well as the number of cited articles Maximum dissemination of your research work

Submit your manuscript at: http://papersubmission.scirp.org/

Or contact ojem@scirp.org 